\title{
PERANCANGAN PERAHU PEMBERSIH SAMPAH DI ALIRAN SUNGAI KOTA BANJARMASIN
}

\author{
${ }^{(1)}$ Muhammad Firman, ${ }^{(2)}$ Muhammad Irfansyah \\ ${ }^{(1)(2)}$ Teknik Mesin,Fakultas Teknik Universitas Islam Kalimantan MAB \\ Jl. Adhiyaksa No. 2 Kayu Tangi, Banjarmasin \\ Email : firmanuniska99@gmail.com
}

\begin{abstract}
Abstrak
Upaya dari pemerintah daerah di kalimantan selatan untuk mengembalikan fungsi sungai melalui kegiatan aksi bersih-bersih aliran sungai khususnya kota banjarmasin sudah mulai menjadi perhatian masyarakat dan pemko, untuk menjadikan kota banjarmasin sebagai destinasi wisata air seperti halnya amsterdam. Namun masih belum secara menyeluruh, karena ternyata masih banyak sampah-sampah di aliran sungai kecil yang sulit di bersihkan. Untuk itu sangat perlu adanya koordinasi yang lebih baik dalam menjaga kebersihan lingkungan. Di banjarmasin dalam mengatasi permasalahan sampah sungai sudah menggunakan kapal pembersih sampah untuk sungai besar, sedangkan untuk anak sungai yang kecil-kecil lebih kurang lebarnya antara $2 \mathrm{~m}$ sampai 4 meter ada yang menggunakan sampan seadanya yang mana petugas kebersihannya kalau membersihkan sungai tersebut terjun kesungai untuk memunguti sampah sedangkan perahunya untuk penampungan sampah sementara sebelum dibuang kepembuangan sampah akhir. Atas dasar itulah maka sangat diperlukan sebuah desain perahu pembersih sampah yang sesuai dengan kondisi sungai di kota banjarmasin. Sehingga kegiatan bersih-bersih tersebut benar-benar efektif dan efesien. Dari hasil analisa dan perhitungan yang dilakukan maka dapat disimpulkan sebagai berikut: Desain perahu pengangkut sampah sudah sesuai dengan yang diharapkan supaya mampu beroperasi di sungai kecil, sempit dan mampu bekerja pada kondisi air dangkal. Kemampuan apung yang didapatkan adalah sebesar $=4716,648 \mathrm{~N}$, Jika perahu saat kosong bagian perahu yang tidak tenggelam adalah sebesar 3436,7069 N, Sedangkan jika berat perahu terisi maksimal bagian perahu yang tidak tenggelam adalah sebesar 984,2069 N. Titik berat penampang perahu terletak pada $\mathrm{Z}(\mathrm{Xo}, \mathrm{Yo})=\mathrm{Z}(1650 \mathrm{~mm}, 750 \mathrm{~mm})$.
\end{abstract}

Kata kunci: perahu, sampah, sungai

\begin{abstract}
The efforts of the local government in South Kalimantan to restore river functions through the action of cleaning the river, especially the Banjarmasin city, have begun to become a concern of the community and Pemko, to make the city of Banjarmasin as a water tourism destination like Amsterdam. But it is still not comprehensive, because it turns out there are still a lot of garbage in the small river which is difficult to clean. For this reason, there is a need for better coordination in maintaining environmental cleanliness. In banjarmasin in overcoming the problem of river waste, it has used garbage cleaning vessels for large rivers, while for small tributaries, the width is less than $2 \mathrm{~m}$ to 4 meters, there are those who use makeshift canoes where cleaning officers clean the river plunges into the river to collect trash while the boat is for temporary trash storage before being dumped to the final garbage disposal. For this reason, it is
\end{abstract}


very necessary to design a garbage cleaning boat that is in accordance with the conditions of the river in the city of Banjarmasin. So that clean-up activities are truly effective and efficient. From the results of the analysis and calculations carried out, it can be concluded as follows: The design of the garbage transport boat is in accordance with what is expected to be able to operate in small, narrow rivers and able to work in shallow water conditions. The buoyancy capability obtained is equal to $=4716,648 \mathrm{~N}$. If the boat is empty, the part of the boat that does not sink is 3436,7069 N. Meanwhile, if the boat weight is fully loaded, the part of the boat that is not sinking is 984,2069 N. located at $Z(X o, Y o)=Z(1650 \mathrm{~mm}, 750 \mathrm{~mm})$.

Keywords: boat, garbage, river.

\section{PENDAHULUAN}

Banjarmasin merupakan salah satu pintu gerbang kegiatan ekonomi nasional. Pulau yang terkenal dengan julukan pulau seribu sungai ini memiliki sebuah bandar pelabuhan besar dan sudah puluhan tahun menjadi pintu keluar masuk bagi kegiatan perekonomian pulau kalimantan, khususnya kalimantan selatan. Tetapi saat ini fungsi sungai tidak di kelola dengan maksimal sering tercemar oleh sampah-sampah yang dibuang sembarangan. Sungai akhirnya kotor dan terlihat tidak indah. Sampah juga menjadi salah satu sebab tenjadinya banjir. Upaya dari pemerintah daerah di kalimantan selatan untuk mengembalikan fungsi sungai melalui kegiatan aksi bersih-bersih aliran sungai khususnya kota banjarmasin sudah mulai menjadi perhatian masyarakat dan pemko, untuk menjadikan kota banjarmasin sebagai destinasi wisata air seperti halnya amsterdam. Dibanjarmasin dalam mengatasi permasalahan sampah sungai sudah menggunakan kapal pembersih sampah untuk sungai besar, sedangkan untuk anak sungai yang kecil-kecil lebih kurang lebarnya antara $2 \mathrm{~m}$ sampai 4 meter ada yang menggunakan sampan seadanya yang mana petugas kebersihannya kalau membersihkan sungai tersebut terjun kesungai untuk memunguti sampah sedangkan perahunya untuk penampungan sampah sementara sebelum dibuang kepembuangan sampah akhir. Data dari Dinas Kimprasko Banjarmasin menunjukkan pada 1997 di Ibu Kota Kalimantan Selatan itu terdapat 117 sungai, kemudian pada 2002 berkurang menjadi 70 sungai, lalu pada 2004 sampai sekarang hanya tinggal 60 sungai. Penataan kota Banjarmasin semestinya penataan daratan harus mengikuti penataan sungai, artinya penataan sungai yang didahulukan baru penataan daratan. Untuk sungai kecil kebanyakan sampah rumah tangga, ada pampers, kantong plastik, kertas, pokoknya sampah rumah tangga dan tanaman cenggondok yang tumbuh subur sehingga menutupi hampir sebagian besar permukaan sungainya yang menyebabkan pendangkalan dan sulit untuk dilewati perahu. Atas dasar itulah maka sangat diperlukan sebuah desain perahu pembersih sampah yang sesuai dengan kondisi sungai di kota banjarmasin. Sehingga kegiatan bersihbersih tersebut benar-benar efektif dan efesien.

Berdasarkan latar belakang penelitian di atas, maka peneliti mengidentifikasi permasalahan yang berkaitan dengan Perancangan Perahu Pembersih Sampah Di Aliran Sungai Kota Banjarmasin. Untuk memperjelas permasalahan yang akan diteliti, maka masalah tersebut dirumuskan sebagai berikut: Bagaimana merancang sebuah perahu pengangkut sampah yang mampu beroperasi di sungai kecil, sempit dan mampu bekerja pada kondisi air dangkal? Berapa kemampuan 
apungnya jika diberi beban maksimum? Dimana letak koordinat kesetimbangannya? Sedangkan tujuan dari perancangan ini adalah untuk mengetahui model perancangan sebuah perahu pengangkut sampah yang mampu beroperasi di sungai kecil, sempit dan mampu bekerja pada kondisi air dangkal, untuk mengetahui seberapa besar kemampuan apungnya jika diberi beban maksimum dan untuk mengetahui koordinat kesetimbangannya. Penelitian ini kami batasi hanya pada bahan yang digunakan untuk pelampung adalah plat aluminium dengan tebal $3 \mathrm{~mm}$, rangka dan bahan pendukung lainnya dari bahan Aluminium karena anti karat, panjang perahu lebih kurang $330 \mathrm{~cm}$ dan lebarnya $150 \mathrm{~cm}$, kapasitas penumpang $150 \mathrm{~kg}$

\section{METODE PENELITIAN}

Penelitian ini dilakukan dengan menggunakan metode atau pendekatan secara teoritis dan analisis. Kajian secara teoritis untuk mendapatkan parameter-parameter utama, dengan berbagai sumber literatur baik berupa buku teks, jurnal maupun yang bersumber dari internet.

\section{Tempat dan waktu penelitian}

Tempat pelaksanaan penelitian ini adalah di Kota Banjarmasin dan Waktu pelaksanaan penelitian dilakukan pada bulan September 2018 sampai dengan bulan April 2019. Penelitian ini dilakukan dengan tiga tahapan yaitu: Tahap Pertama adalah studi kepustakaan (bibliography research), untuk menemukan teori-teori mengenai perancangan perahu pembersih sampah disungai, serta untuk melakukan identifikasi terhadap permasalahanpermasalahan yang sering muncul. Target atau indikator keberhasilan pada tahap ini adalah teridentifikasinya permasalahan tentang bagaimana merancang sebuah perahu pengangkut sampah yang mampu beroperasi di sungai kecil, sempit dan mampu bekerja pada kondisi air dangkal, menggambar rancangan perahu pembersih sampah disungai. Tahap Kedua dari gambar rancangan tersebut selanjutnya di analisa sehingga nantinya dapat menentukan kesetimbangan dari perahu tersebut dan menentukan berapa beban maksimum yang mampu ditahan oleh perahu pembersih sampah tersebut saat beroperasi sehingga tidak tenggelam. Tahap Ketiga berisikan simpulan dari hasil-hasil perhitungan dan analisa data yang telah dilakukan.

\section{HASIL DAN PEMBAHASAN}

Gambar Desain Kapal

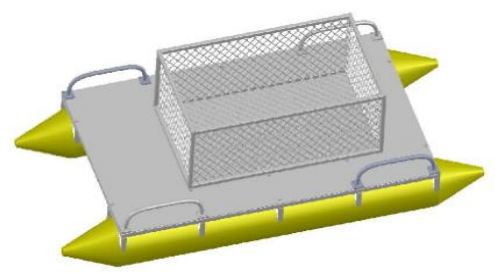

Menghitung Berat Pelampung

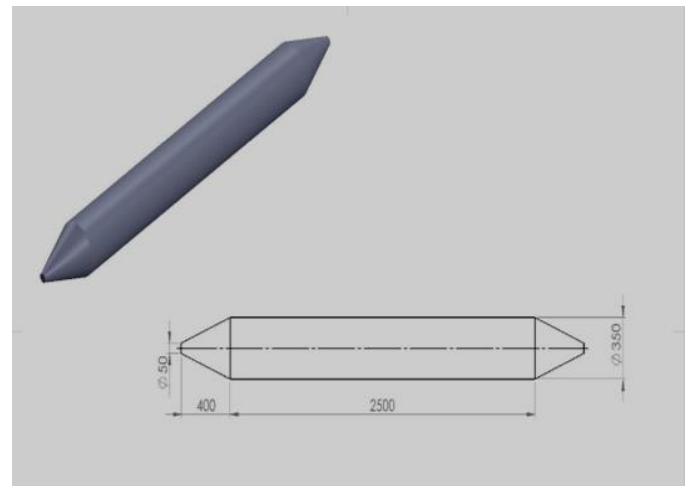

Bahan pelampung aluminium dengan

Berat jenis $(\mathrm{Bj})=2,7 \mathrm{Kg} / \mathrm{dm}^{3}$

Panjang pelampung $(\mathrm{P})=2500 \mathrm{~mm}$

Diameter pelampung $=350 \mathrm{~mm}$

Tebal plat pelampung $(\mathrm{t})=3 \mathrm{~mm}$

Berat pelampung ( Wp ):

$\mathrm{Wp}=\mathrm{V} \times \mathrm{Bj}$

Dimana :

$\mathrm{V}=$ Volume pelampung $\left(\mathrm{dm}^{3}\right)$

$$
V=t \cdot \pi \cdot\left\{(P . D p)+\left(2 \cdot \frac{1}{4} \cdot D p^{2}\right)\right\}
$$




$$
\begin{aligned}
V= & 3 \cdot 3,14 \cdot\{(2500 \cdot 350) \\
& \left.\quad+\left(2 \cdot \frac{1}{4} \cdot 350^{2}\right)\right\} \\
= & 9,42 \cdot\{875000+61250\} \\
= & 9,42 \cdot 936250 \\
= & 8819475 \mathrm{~mm}^{3} \\
= & 8,8195 \mathrm{dm}^{3} \\
\mathrm{Wp} & =\text { Berat pelampung }(\mathrm{kgf}) \\
\mathrm{Wp}= & 8,8195 \cdot 2,7 \\
= & 23,8127 \mathrm{kgf}
\end{aligned}
$$

Karena ada dua buah pelampung maka berat nya menjadi:

$\mathrm{Wp}=2 \times 23,8127$

$=47,6254 \mathrm{kgf}$

\section{Menghitung Berat Kerucut}

\section{Pelampung}

Diameter kerucut $(\mathrm{Dk})=350 \mathrm{~mm}$

Jari-jari kerucut $(\mathrm{rk})=175 \mathrm{~mm}$

Tinggi kerucut $(\mathrm{Tk})=400 \mathrm{~mm}$

Berat kerucut ( Wk ):

$\mathrm{Wk}=\mathrm{Vk} \times \mathrm{Bj}$

Dimana :

$\mathrm{Vk}=$ Volume kerucut $\left(\mathrm{dm}^{3}\right)$

$$
\begin{aligned}
& V=\frac{1}{3} \cdot \pi \cdot\left(r^{2}\right) \cdot T k \\
& V=\frac{1}{3} \cdot 3,14 \cdot\left(175^{2}\right) \cdot 400 \\
= & 128316,6667 \mathrm{~mm}^{3} \\
= & 0,1282 \mathrm{dm}^{3} \\
\mathrm{Wk}= & \text { Berat kerucut }(\mathrm{kgf}) \\
\mathrm{Wk}= & 0,1282 \times 2,7 \\
= & 0,3461 \mathrm{kgf}
\end{aligned}
$$

Karena ada empat buah kerucut pada pelampung maka berat semua kerucut adalah:

$\begin{aligned} \mathrm{Wk} & =4 \times 0,3461 \\ & =1,3844 \mathrm{kgf}\end{aligned}$

$$
=1,3844 \mathrm{kgf}
$$

Menghitung Berat Panel Pelampung

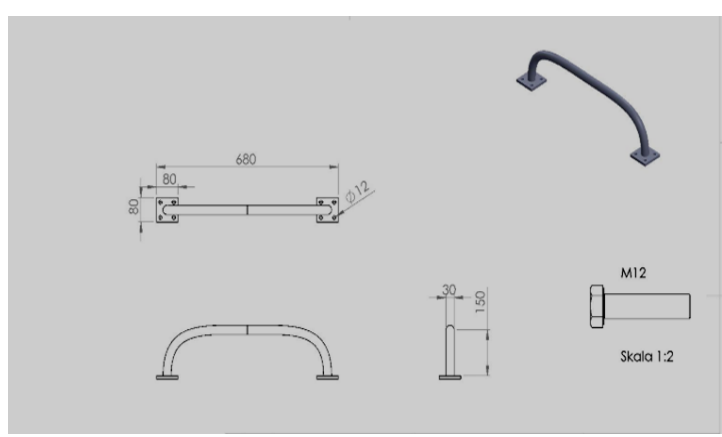

Bahan aluminium dengan berat jenis (

$\mathrm{Bj})=2,7 \mathrm{~kg} / \mathrm{dm}^{3}$

Panjang panel $(\mathrm{Ppn})=950 \mathrm{~mm}$

Diameter panel $($ Dpn $)=30 \mathrm{~mm}$

Tebal panel $(\mathrm{tpn})=3 \mathrm{~mm}$

Berat panel ( Wpn ):

$\mathrm{Wpn}=\mathrm{Vpn} \times \mathrm{Bj}$

Dimana :

Vpn $=$ Volume panel $\left(\mathrm{dm}^{3}\right)$

$$
\begin{aligned}
& \begin{aligned}
V p n=t \cdot \pi \cdot\{ & (\text { Ppn } \cdot D p n) \\
& \left.+\left(2 \cdot \frac{1}{4} \cdot D p n^{2}\right)\right\}
\end{aligned} \\
& \begin{aligned}
V=3 \cdot 3,14 \cdot\{( & (950 \cdot 30) \\
& \left.+\left(2 \cdot \frac{1}{4} \cdot 30^{2}\right)\right\}
\end{aligned} \\
& =9,42 \cdot\{28500+450\} \\
& =272709 \mathrm{~mm}^{3} \\
& =0,2727 \mathrm{dm}^{3}
\end{aligned}
$$

$\mathrm{Wpn}=$ Berat panel $(\mathrm{kgf})$

$\mathrm{Wpn}=0,2727 \times 2,7$

$$
=0,7363 \mathrm{Kg}
$$

\section{Menghitung Berat Pelat Panel}

\section{Pelampung}

Panjang plat panel ( Ppp $)=80 \mathrm{~mm}$

Lebar plat panel $(\mathrm{Lpp})=80 \mathrm{~mm}$

Tebal plat panel $(\mathrm{tpp})=3 \mathrm{~mm}$

Volume plat paner ( Vpp ) :

$$
\begin{aligned}
\text { Vpp } & =\text { Ppp } \times \text { Lpp } \times \text { Tpp } \\
& =80 \times 80 \times 3 \\
& =19200 \mathrm{~mm}^{3} \\
& =0,0192 \mathrm{dm}^{3} \\
\mathrm{Wpp} & =\text { Berat plat panel }(\mathrm{kgf}) \\
\mathrm{Wpp} & =0,0192 \times 2,7 \\
& =0,0518 \mathrm{kgf}
\end{aligned}
$$

Karena ada dua buah plat panel dalam satu panel maka berat nya menjadi:

$\mathrm{Wpp}=2 \times 0,0518$

$$
=0,1036 \mathrm{kgf}
$$

Berat panel total ( Wpt ) adalah berat panel total ditambah jumlah panelnya yaitu 4 buah :

$$
\begin{aligned}
\mathrm{Wpt} & =(\mathrm{Wpn}+\mathrm{Wpp}) \times 4 \\
& =(0,7363+0,1036) \times 4 \\
& =0,8399 \times 4 \\
& =3,3596 \mathrm{kgf}
\end{aligned}
$$




\section{Menghitung Berat Kerangka Lantai}

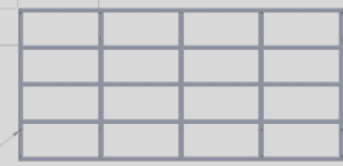

Bahan aluminium dengan berat jenis ( $\mathrm{Bj})=2,7 \mathrm{~kg} / \mathrm{dm}^{3}$

Panjang $2500 \mathrm{~mm}$ ada dua buah, jadi

$2500 \mathrm{~mm} \times 2=5000 \mathrm{~mm}$

Panjang $1500 \mathrm{~mm}-60 \mathrm{~mm}=1440 \mathrm{~mm}$. $1440 \mathrm{~mm}$ ada lima buah, jadi $1440 \mathrm{~mm}$ x $5=7200 \mathrm{~mm}$.

Panjang 587,5 $\mathrm{mm}$ ada dua belas buah, jadi 587,5 mm x $12=7050 \mathrm{~mm}$.

Maka Panjang kerangka seluruhnya

$\left(\mathrm{Pkl}_{1}\right)$ adalah:

$\mathrm{Pkl}_{1}=5000+7200+7050=19250$

$\mathrm{mm}$.

Lebar Rangka $\left(\mathrm{Lr}_{1}\right)=40 \mathrm{~mm}$.

Tinggi rangka $\left(\operatorname{Tr}_{1}\right)=40 \mathrm{~mm}$.

Karena tebal rangka $3 \mathrm{~mm} \times 2=6 \mathrm{~mm}$, maka:

$\mathrm{Pkl}_{2}=19250 \mathrm{~mm}-6 \mathrm{~mm}=19244$

$\mathrm{mm}$

$\mathrm{Lr}_{2}=40 \mathrm{~mm}-6 \mathrm{~mm}=34 \mathrm{~mm}$

$\mathrm{Tr}_{2}=40 \mathrm{~mm}-6 \mathrm{~mm}=34 \mathrm{~mm}$

Menghitung volume kerangka lantai

(Vkl)

$\mathrm{Vkl}=\left(\mathrm{Pkl}_{1} \cdot \mathrm{Lr}_{1} \cdot \mathrm{Tr}_{1}\right)-\left(\mathrm{Pkl}_{2} \cdot \mathrm{Lr}_{2}\right.$.

$\operatorname{Tr}_{2}$ )

$34.34)$

$$
=(19250.40 .40)-(19244 .
$$

$\mathrm{mm}^{3}$

$$
=30800000 \mathrm{~mm}^{3}-22246064
$$

$$
=8553936 \mathrm{~mm}^{3} / 1000000
$$$$
=8,5539 \mathrm{dm}^{3}
$$

Berat kerangka lantai ( $\mathrm{Wkl})$ :

$\mathrm{Wkl}=\mathrm{Vkl} \times \mathrm{Bj}$

$$
\begin{aligned}
& =8,5539 \mathrm{dm}^{3} \times 2,7 \mathrm{~kg} / \mathrm{dm}^{3} \\
& =23,0955 \mathrm{kgf} .
\end{aligned}
$$

\section{Menghitung Berat Lantai Pelampung (WL)}

Bahan aluminium dengan berat jenis (

$\mathrm{Bj})=2,7 \mathrm{~kg} / \mathrm{dm}^{3}$

Panjang lantai $(\mathrm{PL})=2500 \mathrm{~mm}$

Lebar lantai $(\mathrm{LL})=1500 \mathrm{~mm}$

Tebal lantai $(\mathrm{TL})=3 \mathrm{~mm}$, maka:
Volume lantai (VL) adalah:

$\mathrm{VL}=\mathrm{PL} . \mathrm{LL} . \mathrm{TL}$

$$
\begin{aligned}
& =2500 \cdot 1500 \cdot 3 \\
& =1125000 \mathrm{~mm}^{3} / 1000000 \\
& =11,25 \mathrm{dm}^{3} .
\end{aligned}
$$

Berat lantai ( WL):

$$
\begin{aligned}
\mathrm{WL} & =\mathrm{VL} \times \mathrm{Bj} \\
& =11,25 \mathrm{dm}^{3} \times 2,7 \mathrm{~kg} / \mathrm{dm}^{3} \\
& =30,375 \mathrm{kgf} .
\end{aligned}
$$

\section{Menghitung Berat Tempat Sampah} Total ( $\left.\mathbf{W}_{\text {TST }}\right)$

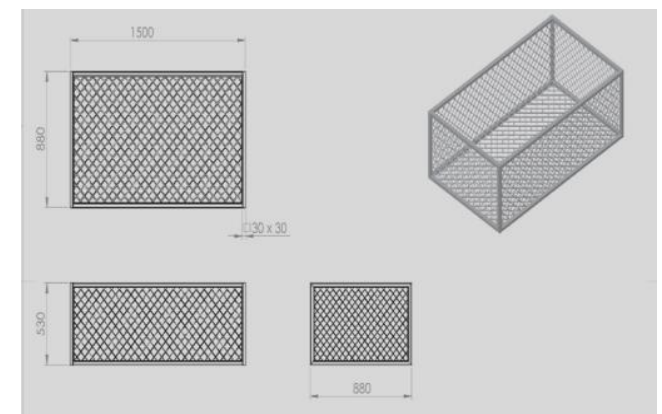

Bahan aluminium dengan berat jenis ( Bj ) $=2,7 \mathrm{~kg} / \mathrm{dm}^{3}$

Panjang tempat sampah $\left(\mathrm{P}_{\mathrm{TS}}\right)=1500$ $\mathrm{mm}$

Lebar tempat sampah $\left(\mathrm{L}_{\mathrm{TS}}\right)=800 \mathrm{~mm}$ Tinggi tempat sampah $\left(\mathrm{T}_{\mathrm{TS}}\right)=1000$ mm.

Maka:

Untuk ukuran 800 x 1000 ada 2 buah Untuk ukuran 1500 x 1000 ada 2 buah Tebal $2 \mathrm{~mm}$

Jadi untuk volumenya adalah:

$$
\begin{aligned}
\mathrm{V}_{\mathrm{TS} 1} & =800 \times 1000 \times 2 \\
& =1600000 \mathrm{~mm}^{3} / 1000000 \\
& =1,6 \mathrm{dm}^{3}
\end{aligned}
$$

Berat tempat sampah ( $\left.\mathrm{W}_{\mathrm{TS} 1}\right)$ :

$$
\begin{aligned}
\mathrm{W}_{\mathrm{TS} 1} & =\mathrm{V}_{\mathrm{TS} 1} \times \mathrm{Bj} \\
& =1,6 \mathrm{dm}^{3} \times 2,7 \mathrm{~kg} / \mathrm{dm}^{3} \\
& =4,32 \mathrm{kgf} . \\
\mathrm{V}_{\mathrm{TS} 2} & =1500 \times 1000 \times 2 \\
& =3000000 \mathrm{~mm}^{3} / 1000000 \\
& =3 \mathrm{dm}^{3}
\end{aligned}
$$

Berat tempat sampah ( $\mathrm{W}_{\mathrm{TS} 1}$ ):

$$
\begin{aligned}
\mathrm{W}_{\mathrm{TS} 2} & =\mathrm{V}_{\mathrm{TS} 2} \times \mathrm{Bj} \\
& =3 \mathrm{dm}^{3} \times 2,7 \mathrm{~kg} / \mathrm{dm}^{3} \\
& =8,1 \mathrm{kgf} .
\end{aligned}
$$

Jadi berat tempat sampah total ( $\left.\mathrm{W}_{\mathrm{TST}}\right)$

$\mathrm{W}_{\mathrm{TST}}=\left(\mathrm{W}_{\mathrm{TS} 1}+\mathrm{W}_{\mathrm{TS} 2}\right) \times 2$ $=(4,32+8,1) \times 2$ 


$$
=24,48 \mathrm{kgf} \text {. }
$$

\section{Menghitung Berat Kapal Saat}

\section{Kosong (Wksk)}

$\mathrm{Wksk}=\mathrm{Wp}+\mathrm{Wkp}+\mathrm{W} 4 \mathrm{p}+\mathrm{Wkl}+$

$\mathrm{WL}+\mathrm{WTS}$

$$
\begin{aligned}
& =47,6254+1,3848+3,1524+ \\
& 23,0955+30,375+24,84 \\
& =130,4731 \mathrm{kgf} .
\end{aligned}
$$

Menghitung Berat Kapal Saat Penuh (Wksp)

Data yang di tentukan adalah:

Berat kapal kosong $($ Wksk $)=130,4731$

$\mathrm{Kg}$

Berat sampah $=300 \mathrm{~kg}$

Berat penumpang 4 orang $=300 \mathrm{Kg}$

Jadi berat kapal saat penuh (Wksp)

adalah:

$$
\begin{aligned}
\text { Wksp } & =\text { Wksk }+ \text { Ws }+ \text { W4p } \\
& =130,4731+100+150 \\
& =380,4731 \mathrm{kgf} .
\end{aligned}
$$

\section{Menghitung Kemampuan Apung \\ Perahu}

Data yang didapat:

Berat pelampung $=23,8127 \mathrm{kgf}$

Diameter pelampung $=350 \mathrm{~mm}=0,35$ $\mathrm{m}$

Panjang pelampung $(\mathrm{Pp})=2500 \mathrm{~mm}=$ 2,5 m

- Menentukan volume pelampung $(\mathrm{Vp})$

$$
\begin{aligned}
\mathrm{Vp} & =\pi \times\left(\mathrm{r}^{2}\right) \times \mathrm{Pp} \\
& =3,14 \times\left(0,175^{2}\right) \times 2,5 \\
& =0,2404 \mathrm{~m}^{3}
\end{aligned}
$$

- Menentukan gaya apung pelampung (Fap)

Fap $=V p \times \rho \times g$

Dimana:

Fap = gaya apung pelampung $(\mathrm{N})$

$\rho \quad=$ massa jenis air $\left(\mathrm{kg} / \mathrm{m}^{3}\right)=$ $1000 \mathrm{~kg} / \mathrm{m}^{3}$

$\mathrm{g}=$ percepatan grafitasi $(\mathrm{N} / \mathrm{kg})=$ $9,81 \mathrm{~N} / \mathrm{kg}$

Jadi gaya apung pelampung adalah:

Fap $=0,2402 \times 1000 \times 9,81$

$$
=2358,324 \mathrm{~N}
$$

Karena ada dua pelampung maka kemampuan apungnya adalah:

Fap $=2358,324 \times 2$

$$
=4716,648 \mathrm{~N}
$$

Jika berat perahu saat kosong adalah $130,4731 \mathrm{kgf}$

Gaya grafitasi $(\mathrm{Fg})=$ Berat perahu kosong x $\mathrm{g}$

$\mathrm{Fg}=130,4731 \mathrm{kgf} \times 9,81 \mathrm{~N} / \mathrm{kgf}$ $=1279,9411 \mathrm{~N}$

Maka bagian perahu yang tidak tenggelam adalah sebesar:

Fapk $=4716,648 \mathrm{~N}-1279,9411 \mathrm{~N}$

$$
=3436,7069 \mathrm{~N}
$$

Sedangkan jika berat perahu terisi maksimal adalah:

Jadi berat kapal saat penuh (Wksp) adalah 430,4731 kgf.

Gaya grafitasi $(\mathrm{Fg})=$ Berat perahu maksimal x $\mathrm{g}$

$$
\begin{aligned}
\mathrm{Fg} & =380,4731 \mathrm{kgf} \times 9,81 \mathrm{~N} / \mathrm{kgf} \\
& =3732,4411 \mathrm{~N}
\end{aligned}
$$

Maka bagian perahu yang tidak tenggelam adalah sebesar:

Fapk $=4716,648 \mathrm{~N}-3732,4411 \mathrm{~N}$

$$
=984,2069 \mathrm{~N}
$$

\section{Menentukan Koordinat Titik Berat Perahu}

Data yang diketahui adalah:

Panjang total perahu $=2500 \mathrm{~mm}+$ (400 mm x 2 )

$$
=3300 \mathrm{~mm}=3,3
$$

$\mathrm{m}$

Lebar total perahu $\quad=1500 \mathrm{~mm}=1,5$ $\mathrm{m}$

Berat total perahu $\quad=130,4731 \mathrm{kgf}$ Titik berat penampang perahu terletak pada:

$$
\begin{aligned}
& X o=\frac{(\epsilon G \cdot x)}{\epsilon G} \\
& =\frac{(380,4731 \mathrm{kgf} \cdot 1650 \mathrm{~mm})}{380,4731 \mathrm{kgf}} \\
& =1650 \mathrm{~mm} \\
& Y o=\frac{(\epsilon G \cdot y)}{\epsilon G} \\
& =\frac{(380,4731 \mathrm{kgf} \cdot 750 \mathrm{~mm})}{380,4731 \mathrm{kgf}} \\
& =750 \mathrm{~mm}
\end{aligned}
$$

Jadi koordinat titik beratnya berada $\mathrm{Z}($ Xo , Yo $)=Z(1650 \mathrm{~mm}, 750 \mathrm{~mm})$ 


\section{KESIMPULAN}

Dari hasil analisa dan perhitungan yang

dilakukan maka dapat disimpulkan

sebagai berikut:

1. Desain perahu pengangkut sampah sudah sesuai dengan yang diharapkan supaya mampu beroperasi di sungai kecil, sempit dan mampu bekerja pada kondisi air dangkal.

2. Kemampuan apung yang didapatkan adalah sebesar $=4716,648 \mathrm{~N}, \quad$ Jika perahu saat kosong bagian perahu yang tidak tenggelam adalah sebesar 3436,7069 N, Sedangkan jika berat perahu terisi maksimal bagian perahu yang tidak tenggelam adalah sebesar 984,2069 N

3. Titik berat penampang perahu terletak pada $\mathrm{Z}(\mathrm{Xo}, \mathrm{Yo})=\mathrm{Z}(1650$ $\mathrm{mm}, 750 \mathrm{~mm}$ ).

\section{REFERENSI}

[1] M. Orianto, W.A Pratikto. 1984. Mekanika Fluida I. Surabaya. Robert J. Kodoatie. 2009. Hidrolika Terapan Aliran pada Saluran Terbuka dan Pipa. Yogyakarta.

[2] Journal: Isa Rachman*), Lilik Subiyanto, Gaguk Suhardjito, and Arie Indartono. 2014. "Identifikasi Garis Stabilitas Melintang Kapal Melalui Percobaan Kemiringan Menggunakan Delphi Berbasis Arduino" . TRANSMISI 16 (3) 2014. 121-127.

[3] Febriana Dian Krismawati, Ahmad Fauzan Zakki, Parlindungan Manik. "Perancangan Bangunan Apung Dan Keramba Dengan Sistem Modular Ponton Berbahan
Ferosemen". Jurnal Teknik Perkapalan - Vol. 4, No.3 Bulan 2014. 66-73.

[4] Rujukan Elektronik: (https://ilmulaoet.blogspot.com/2012/09/caramenghitung-kapasitas-angkutpontoon.html)

[5] (http://nautikaperkapalan.blogspot.c om/2016/07/stabilitaskapal_24.html) 